\title{
1 Calm ICT design in hotels: A critical review of applications and 2 implications
}

3

\begin{abstract}
There has recently been a call for revisiting the effect of ICT on guest experience in hotels. This is because ICT solutions can act not only as enhancers of hotel guest experience, but also as its inhibitors. In response to this call, the notion of calm ICT design has recently been introduced. Calm ICT design describes the ICT solutions that are used only when and if required, thus not calling user's attention at all times. Although this concept is highly relevant to the hospitality industry, it has never been systematically considered within. This paper conceptualizes calm ICT design for application in the hospitality context. To this end, it analyzes the ICT solutions that are currently employed by hospitality businesses from the calm ICT design perspective; discusses how the opportunities offered by calm ICT design can be better capitalized upon by hospitality managers; and outlines directions for future research.
\end{abstract}

Key words: technology, hotel, guest experience, calm ICT design

\section{Introduction}

The use of ICT adds a new dimension to the complete modern hotel experience (Buhalis \& Leung, 2018; Sarmah, Kamboj, \& Rahman, 2017; Sigala, 2018). In the context of co-creation of experiences, ICT is more than just an ordinary tool (Neuhofer, Buhalis, \& Ladkin, 2012) offering various possibilities for experience enhancing. As a result, the positive role of ICT has been widely recognized in the hospitality literature (Law, Buhalis, \& Cobanoglu, 2014). However, ICT can also diminish or even destroy the hotel guest experience through, for example, technological failures and visual or noise pollution (Benckendorff, Sheldon, \& Fesenmaier, 2014), information overload (Friás et al., 2008), technostress (Lee et al., 2014), poor design (Benckendorff et al., 2014) and depersonalized hotel experience (Tarlow, 2011). Hence, the "by default” integration of ICT solutions into hotel experience with an intention of value creation and enhancement may not always work as intended (Neuhofer, 2016) and can even lead to „value co-destruction“ instead (Plé \& Chumpitaz Cáceres, 2010). Value co-destruction happens when ICT does not deliver its ultimate purpose to consumers due to hotel guest disengagement with technology or due to inadequate technology design and implementation. An example of this would be a situation when hotel guests have limited knowledge of a new ICT solution and are therefore unable to use it as expected by a technology provider (hotel) (Plé \& Chumpitaz Cáceres, 2010). Alarmingly, although the issue of technological overload has potential to inhibit hotel guest 
experience, it has largely been overlooked by the industry practitioners to date (Cobanoglu et al., 2011).

The detrimental effect of prospective technological overload on consumer experience

has been envisioned back in the early 1990s, i.e. long before the era of omnipresent computing. Weiser and Brown (1995) raised first concerns about potential, computerimposed, information overload and the subsequent stress this overload creates for technology users (Byrne et al., 2009; Greenfield, 2006). As a partial solution, Weiser and Brown (1995) introduced the concept of 'calm technology' which advocates the design of technology from the perspective of its users, rather than providers. 'Calm technology' is the context in which technology recedes into the background of people’s lives (Mark Weiser \& Brown, 1995), drawing the end user's attention only if and when necessary. Case (2015) has further suggested that the term 'calm interaction' or simply 'calm design' may be more accurate than 'calm technology' as it implies that technology is used for a smooth capture of the end user's attention only when required, while calmly remaining in the background at most times. The ultimate purpose of calm design is not to calm people physiologically, emotionally or cognitively, but to design ICT solutions that can be more easily used in a calm manner (Moraveji et al., 2011; Stanford University's Calming Technology Lab, 2011). With the rapid development of the Internet and with smart technologies getting better embedded and more seamlessly integrated into everyday objects, the concept of calm ICT design is gaining popularity in ubiquitous computing and ambient intelligence as well as in product design (Case, 2015a; Elwood, 2010; Hohl, 2009; Rogers, 2006; Weiser \& Brown, 1995).

The concept of calm ICT design is underpinned by the idea that technology has no purpose by itself, but it should serve in delivering a desired experience (Case, 2015). For example, when applied in the hospitality context, calm ICT design should facilitate delivery of a pleasant and stress-free hotel experience. Calm ICT design can be integrated into the items used by the hotel guests the most, such as smartphones and wearables, as well as into more sophisticated and yet less frequently employed technological solutions in hospitality management, such as the video display units and the biometric technologies. Although calm ICT design has become a significant factor for everyday product development (Case, 2015a), its implications for hotel management remain poorly understood.

In order to understand the implications of calm ICT design for hotel guest experience, a narrative review of the key existing and forthcoming support technology infrastructure should be undertaken. To this end, this paper conducts a critical analysis of the literature on contemporary ICT solutions in hospitality to better understand the potential for application of calm ICT design in hotels. Thus, this review paper fills the gap in the literature on the employment of calm ICT design in hotels. By outlining directions for future research, the paper further contributes to the ongoing academic discourse on the use of smart technologies and disruptive ICT solutions within hotels. 
In their seminal work, Weiser and Brown (1995) divided technologies into calm and disturbing. The differentiation was made on the grounds of how technologies engage with the user's central and peripheral attention. Calm technology should engage with both and, while it focuses on central attention, peripheral attention is naturally attuned. In terms of audioenabled kitchen appliances, for example, the user's central attention is on the meal preparation while peripheral attention is attuned with subtitle audio notifications when setting up devices. The peripheral attention can suddenly become central and demand action. In the audio-enabled kitchen appliances example, a sudden change in the notification sound level draws users' attention and prompts them to check the water level in the steam cooker, for example. What is fundamentally 'encalming' in this example is a smooth transition from peripheral to central attention and backwards only when needed, while the device is trusted by its user to perform its original task at all other times (Case, 2015).

It is important to recognize that the notion of calm design is not novel. Essentially, it represents a revised approach in technology design which puts end-users in the focus. The intention is to reduce the mental costs for consumers of technology, i.e. technology facilitates end-users to reach a desired goal via the fewest possible number of steps (Case, 2015). Riekki et al. (2004) view this type of "calmness" as a user-centric measure, which describes how a system appears to the user when technology is utilized in a specific context. Therefore, the important aspects of calm technology are: timing (an application interacts with a user in the right situation and at the right time) and the relevance of interaction (interaction fits into a specific situation). In the ambience intelligence context, calm design begins when computer technology vanishes in the background (Bibri, 2015). From one point of a view, the computer disappearance can be seen as physical disappearance, i.e. when computers become small enough to be invisibly embedded into objects or people (for example, smart wearables), or mental disappearance, i.e. when people no longer perceive devices as computers but as integral elements of augmented artifacts in the environment (for instance, interactive screens, holograms, or realistic, augmented reality-based, video games) (Streitz, 2001; Ţugui \& Genete, 2009). Moreover, the “invisibility” of technology is achieved when the users' focus is on the task, not on the tool they use (Weiser, 1993). For example, Google Search would qualify as invisible as its robust search engine is hidden behind the minimalistic omni-channel digital experience that works well enough, so the users tend to forget it even exists (Ocallaghan, 2014; Sension, 2018).

112

Ţugui and Genete (2009) pinpoint the minimum conditions for ICT solutions to become calm, i.e. their adaptability to end-user behavior as enabled by flexible communication; information security and confidentiality of the end-user's private data; universal user interface 
which remains unconditioned and permanent in various environments; invisibility of the material system which functions without excessive user interventions; integration of all of the equipment and applications into a single platform; and constant availability as a result of growing reliance of industry practitioners and consumers upon technology. Case (2015) outlines examples of the practical application of calm design and defines the basic principles and patterns for non-intrusive technology design to ensure it becomes an integral part of an end-user's life, and not a distraction from it. In order for technology to be calm, Case (2015) insists that it should require the smallest possible amount of attention from end-users and, for delivering or extending communication, it should use end-users' peripheral attention. Furthermore, Case (2015) advocates that calm design should encompass the best of technology (for example, its ability to perform complex algorithms) and the best of humanity (for instance, it should contain features enabling end-users to do what they know best, such as recognizing specific contexts and communicating seamlessly with other users). This is based on the principles of affective computing that relate to systems and devices that are able to work with and simulate human emotions (Picard, 1995), such as a robotic companion for the elderly (Sharkey \& Sharkey, 2012) or the educational robots for children with autism (Robins \& Dautenhahn, 2014). Furthermore, Case (2015) points that technology should not necessarily communicate with end-users verbally as interacting via simple audio-visual notifications is often enough. In order to offer a friction free end-user experience, all possible technology failures have to be carefully addressed to enable even least experienced users to deal with technology seamlessly. Ideally, the right amount of technology is the minimum needed to solve the problem. Finally, in order to avoid any tension, calm technology should respect the social norms, as people may need time to get accustomed to certain technological solutions (Case, 2015). Indeed, consumer distrust in a new technology may affect the success of its market penetration and it is thus critical to understand public attitudes to various ICT solutions, especially the novel ones.

Some of the most notable examples of calm ICT design are related to calm communication, such as the different sounds of the status tones, relevant pop-ups or haptic alerts used in wearables. An example is the Dark Sky weather application for hiking that employs user's location, criteria entry and upcoming weather patterns to notify the user when needed but otherwise running calmly in the background (Grossman, 2015). By exploring the possibilities of applying the principles of calm technology in marketing in the era of the Internet of Things (IoT), Sweterlitsch (2016) even coins the term "atmospheric approach" (marketing is invisible, yet it is everywhere), referring to the marketing paradigm that delivers a message quietly and without interruption using peripheral awareness so that customers can choose to attend the message or take action with the least amount of mental cost. In the hospitality context, a good example of calm ICT design is Gustaffo, a digital concierge service for hotels that integrates into existing hotel's ICT solutions, constantly working 
151 behind the scene to address the needs of hotel guests. With this service there is no need for 152 the guests to install a hotel smartphone application, as they can be automatically redirected to 153 the digital concierge which becomes active immediately after the guests have logged into the 154 hotel's WiFi. It can independently read and interpret written or spoken language and give an

155

156

157

158

159

160

161

162

163

164

165

166

167

168

169

170

171

172

173

174

175

176

177

178

179

180

181

182

183

184

185

186

187

appropriate answer (i.e. provide a service) by using the way of communication that the guests choose (for example, Amazon's Alexa, Facebook messenger, Twitter, WeChat, Whatsapp or chat widgets from the hotel homepage) (Gustaffo, 2018). For the guests, this calm ICT design solution reduces the barrier of technology use and, for the hotels, it offers better opportunities to promote its services.

\section{Current hotel ICT solutions and calm ICT design}

To analyze current hotel ICT solutions from the viewpoint of their suitability for calm ICT design, a smart technology paradigm has been utilized. The categorization of current ICT solutions as applied in hotels is based on the key smart technologies (Stankov, Pavluković, Alcántara-Pilar, Cimbaljević, \& Armenski, 2018) and will encompass: smartphones, wearables, biometric and audio-visual technology, as well as the supporting components, including intelligent software agents and geolocation systems.

\section{Smartphones}

Smartphones have changed the communication landscape in the hospitality sector as they have become ubiquitous, providing a key medium for information delivery and exchange (Kim and Law, 2015). The growing number of consumers nowadays own multiple devices and use them consecutively when searching travel information and booking, however, comparing to other devices smartphones are the most portable, versatile and accessible virtually anywhere (Murphy, Chen, \& Cossutta, 2016) including almost all possible scenarios hotel experience. Hoteliers have begun responding to this trend by developing corporate mobile phone use strategies and accompanying applications (Chen, Murphy, \& Knecht, 2016). For example, Radisson RED (Brussels, Belgium) uses all-in-one hotel application to deliver services through the hotel guests' smartphones. Room reservation and seamless control over hotel stay with keyless technologies are enabled by a dedicated app. Everything a guest might need before, during and after their stay is centralized on a single, easy-to-use platform (Assa Abloy, 2016).

The main strengths of smartphones for calm ICT design are related to the fact that mobile applications have shifted from being a novelty to becoming an essential part of consumer experience, with the capabilities of offering personalized information for guests, two-way sharing, context awareness based on smartphone sensors, or communication with 
other machines (Dickinson et al., 2014). Smartphones are therefore able to offer better convenience, flexibility, efficiency and fun for users (Kim and Law, 2015). On the other side, when mobile applications are incorporated into the hotel guest experience, they can distract consumers and reduce calmness. This can be a result of, for instance, poor connectivity, high consumption of battery power, charging issues, limited device processing capabilities or excessive roaming charges. Furthermore, emerging sophisticated hotel services, followed by virtual and augmented reality features, will require additional resources and will impose further pressure on average smartphone processing capabilities (Chiu \& Leung, 2005). Finally, the current mobile app market is saturated (Lunny, 2016) which can increase consumers' unwillingness to install another app just for the purpose of hotel stay.

\section{Wearables}

Wearables encompass various technological solutions that stand for the different forms of body mounted technology (Atembe, 2015). They represent an emerging ICT trend which finds purpose during travel and hotel stay by facilitating communication, navigation, information search or health monitoring (Atembe, 2015; Ortiz Rincon, Tommasini, Rainoldi, \& Egger, 2017; Tussyadiah, 2013). For example, Palladium Hotel Group (Ibiza, Spain) introduced the VIB (Very Important Bracelet). With its smart bracelets, the hotel guests can access rooms and other hotel facilities, pay for products and take advantage of exclusive discounts. The bracelets are programmed to ensure that guests' information is safely protected (Palladium Hotel Group, 2014). Drawing on this example, wearables will become an important ICT solution to be used in the context of all-inclusive holidays where they would replace traditional paper bracelets by offering not only a fashionable hi-tech device, but also a device with integrated functionality.

Some existing wearable technologies represent, in their essence, examples of calm ICT design as they are almost invisible; small-sized and discrete; unobtrusive; easy to set up and use; highly personalized to end-user requirements; with automated action based on sensors and with enabled connectivity with servers. Wearables extend the concept of embedding ubiquitous computing beyond hand-held devices (Elwood, 2010). As such, wearables reveal opportunities to create tailored hotel guest experiences based on consumer location, previously recorded preferences, or even current moods (Choe \& Fesenmaier, 2017; Dibble, 2015). The real value of wearables is in their capability to provide access to vital body parameters (Chan, Estève, Fourniols, Escriba, \& Campo, 2012) and possibly determine user's emotional status; this can be used to deliver more relevant, emotion-based content services in hotels (Lee and Kwon, 2010).

Despite numerous advantages of the use of wearables for calm ICT design, there are some notable weaknesses. Hotels must carefully consider the key drivers of the wearables' adoption in the first place as to figure out how they can be best used in the guest 
accommodation context. Some wearables are not yet widely accepted by the public because of their design and size/bulkiness. Some custom made wearables (bracelets and smart watches) can be too expensive to embrace for small hotels (Little Hotelier, 2015). Lastly, wearables are less versatile compared to the capabilities of hand-held devices and traditional desktop computers (Glaros and Fotiadis, 2005).

\section{Biometric technology}

Biometric technology encompasses various forms - fingerprint and iris scanning, facial, voice, hand geometry or signature recognition - and offer multiple opportunities for hotels (Mills et al., 2010). Biometrics have long been around and the hospitality industry has recently started embracing them to enhance its management and improve quality service delivery, such as providing seamless access for hotel guests to control and payment, time and attendance systems (Kang et al., 2007). Therefore biometrics are gradually becoming a common in-room technological solution for hotels. For example, Waldorf Towers Hotel (New York, USA) uses the Elsafe biometric safe with fingerprint recognition which enables the hotel guests to securely store their personal belongings by applying little effort (Assa Abloy, 2003).

There are several important characteristics of biometric technology that contribute to its calm ICT design, such as the relative easiness of use, speed and reliability, longevity, suitability for many environments (Meyers \& Mills, 2005). Most importantly, biometrics do not necessitate use of extra devices. The biometric access control systems are often seen as a means to make hotel premises safer for guests and to prevent its misuse by criminal elements (Thakkar, 2016).

Despite their multiple advantages, currently, neither guests nor hoteliers are yet fully ready for biometrics (Bilgihan, Karadag, Cobanoglu, \& Okumus, 2013), thus preventing it from being considered as an example of calm ICT design. Biometric identification has to overcome such challenges as under-developed national legislation, user privacy and personal concerns, misunderstanding of the system functioning and high costs of deployment, among others (Kang et al., 2007; Kim, Farrish, \& Schrier, 2013; Neo, Rasiah, Tong, \& Teo, 2014).

\section{Audio-visual technology}

Audio-visual technology is a traditional hotel ICT category that encompasses various video display systems, self service automated machines or innovative voice-controlled systems. For example, Wynn (Las Vegas, USA) was among the first hotels in the world to commercially introduce the Amazon Echo smart speakers as room equipment. Guests can verbally control many aspects of lighting, temperature and the audio-visual components of a hotel room using commands via the voice-activated assistant Alexa service (Raz, 2016). 
Importantly, infrastructure that enables calm ICT design is largely dependent on audiovisual technology. Clarity and consistency are the vital aspects of smart technology use in this context (Tarlow, 2011). Through video displays, important information can be provided to hotel guests in their native language while the consistency of end-user interface (UI) in different locations could be reinforced by adopting popular mobile operating system interfaces. Calm ICT design can utilize advanced combinations of tone, lights or sensory stimulation to suit everyone's taste and mood (Case, 2015). Although human-to-machine communication is still a major problem to overcome (Case, 2015), in the realm of applying calm ICT design in hotels many improvements can be made. Most commonly, if UI calls for all of the user's visual or auditory focus, the envisioned interaction can actually be distracting (Case, 2015).

\section{Intelligent software agents and geolocation systems}

Many ICT solutions presented above are usually underpinned by robust intelligent software agents. Intelligent software agents are an important asset for calm ICT design as they can bridge the gap between computers and specific applications (Hermans, 1998). Most examples of current use of artificial intelligence (AI) in the hospitality sector are related to the back office operations, such as revenue management, marketing or advertising, while there are many other possible applications in daily operation activities that directly affect guests, such as housekeeping, check-in or check-out procedures, predicting of room maintenance work, and food procurement, to mention a few (Alsetoohy \& Ayoun, 2018; Reeves, 2018).

Similarly, geolocation systems are an underlying technology which enables recognition of location that is critical for understanding the spatial context for human-computer interaction in delivering desirable experiences. As such, it is often an indispensable component of all above-mentioned technologies. For example, Hyatt Regency (Santa Clara, USA) uses Cisco high-speed Wi-Fi, as a geolocation system. With the Wi-Fi coverage being seamlessly provided throughout the property, the hotel uses data about guest location and behavior to improve the effectiveness of on-site promotions (one-to-one advertising, delivering notifications) and to increase revenues from its catering and leisure facilities (Cisco, 2015).

Contextual information and communication are one of the most important characteristics of calm ICT design that should be provided by intelligent software agents as they intend to recommend personalized content based on the users' dynamical behavior and the content they create and consume (Wang, Zhu, Cui, Sun, \& Yang, 2013). In that sense, geolocation systems offer opportunities for the development of proximity and location services (Yamamoto, 2009) and enhancing guest experience (Chung, Tyan, \& Han, 2017). For example, proximity marketing and location-based marketing have potential to be "calm" as they represent wireless distribution of the advertising content to the equipped users which 
is localized to a particular place and bordered by invisible geo-fences or edges of transmitters' signal range (Yovcheva et al., 2012). In general, from the end-user viewpoint, geolocation systems represent an easy-to-deploy and enjoyable way of identifying locations (Chung \& Lee, 2016) while complex ICT support services are completely submerged in the background and require no interaction.

In practice, while there are growing examples of contextual notifications in action that come from weather, location, time, metabolic and emotional states or proximity, this area is yet to be developed (Case, 2015). Besides the necessity to have constant access to the mobile equipment in order to participate in proximity marketing supported by geolocation systems, hotel guests must further satisfy a number of preconditions that can be discomforting (for example, Wi-Fi or Bluetooth enabled on smartphones and required application opt-in). In that context, pushed-based personalized messages represent a key obstacle for the application of calm ICT design in services based on geolocation systems as marketers might often try to overwhelm consumers with offers and messages (Balasubramanian, 2009). Finally, there are emerging ethical concerns regarding the potential violation of hotel guests' privacy when using these systems (Hardy et al., 2017) and it is another problem to be solved in terms of calm ICT design as applied in hotels.

\section{Functionality of calm ICT design for hotels}

According to Pizam (2010), the creation of memorable hotel guest experience is a cornerstone of the hospitality industry. This is a challenging task to fulfill given the multidimensional structure of consumer experience which consists of personal characteristics, trip-related determinants, physical environments and human (social) interactions (Cetin \& Walls, 2016; Walls, Okumus, Wang, \& Kwun, 2011). It has been well recognized that ICT solutions can aid hoteliers in the creation of memorable hotel guest experience (Whitelaw, 2008). However, there have also been reports indicating that the incorrect or improper use of ICT in hotels can dissatisfy guests, thus diminishing their experience (Cobanoglu et al., 2011; Kronsberg, 2016). This is because there are novel ICT solutions designed for hospitality management that hotel guests do not always embrace and these are seen as disruptive (Cobanoglu et al., 2011). For example, the ICT solutions for augmenting or replacing interactions between hotel guests and front-line employees can impede development of employee-guest rapport and lead to lower service evaluations (Giebelhausen, 2014).

The advantage of calm ICT design in hotels lies in the fact that it is an attention and focus-based approach that is predominately related to the 'calm' state of a guest that should not shift to the "disturbed" state when consuming hotel services delivered by ICT. Essentially, calm ICT design should help the guest to deal with shortcomings of the ICT uptake in hotels. Consequently, by removing the ICT-induced friction in guest experience, no 
additional mental cost is required which could then increase guest satisfaction. Below we propose the functional strategies that stress the advantages of calm ICT design for hotels.

\section{ICT supported hotel communication}

ICT supported communication is an integral element of hotel experience (Benckendorff et al., 2014; Chen et al., 2016; Ting, 2017). From the calm ICT design perspective it can encompass various contexts of the use of ICT solutions to interact with hotel guests, including: hotel apps working in the background and notifying the end-users only when needed; pull notifications (for examples, from smart posters) (Pesonen \& Horster, 2012), optin push notifications (iBeacon) (Babu, 2015), unified user experiences for e-info points (for example, use of Google Material design for hotel applications) (Cousins, 2015), employment of enhanced visual communication with the use of virtual reality functions on hotel websites (Lee and Oh, 2007) or the use of standard emojis in delivering information (Clark, 2014). The potential 'calmness' of these ICT solutions has been enabled by the advancements in audiovisual technologies and smartphone development alongside their omnipresence. One of the key principles of calm ICT design, which utilizes periphery attention of end-users to communicate additional messages, would require extension of ICT solutions to the physical sphere in order to provide more human-like communication by, for example, using audiovisual or tactile communicators. In that sense, some hotels have adopted tablets to control room appliances and house-keeping services while some hotels employ remote energy control devices with "on/off buttons", voice and light notifications (Wasan, 2014). For example, Marriot actively investigates this system to enable consumers to completely bypass the touch screens or physical button commands (Eye for Travel, 2016).

\section{Guest-host transactions}

The main advantage of calm ICT transactions for guests is the convenience of use which leaves enough space to enjoy the basic hotel experience, as no additional mental cost is needed to conduct practical operations. Guest-host transactions based on calm ICT design encompass examples of paperless transactions (Neo et al., 2014; The Japan News, 2016), contactless identification and payment (Bilolo, Boeck, Durif, Levesque, \& Levesque, 2015), proximity transaction services (Pesonen \& Horster, 2012), self-directed experiences (for example, Starwood's keyless mobile entry) (Ting, 2016; Lim et al., 2018).) or indoor/outdoor visitors tracking without their active participation (Williams, 2015). Most of these transactions are provided with the use of biometric identification technology or, more commonly, with the help of smartphones and wearables. The solutions that are able to provide totally calm ICT transactions include the assets required for information aggregation, ubiquitous mobile connectedness and real time synchronization of information (Neuhofer et 
402

403

al., 2015). Given the present context, calm ICT design provides hotels with the new opportunities to deliver exceptional guest experiences that benefit from simpler and user friendlier processes (Amadeus, 2007).

\section{Branded calm ICT hotel services}

Calm ICT design can aid in the development of new business models; it can further make some traditional hotel services to disappear while some new services to emerge (Tugui \& Genete, 2009). For example, so-called 'digital detox' facilities and silent retreats (LippeMcGraw, 2017) or other 'niche' types of the hotel industry's offers, such as spa \& wellness, rural hotels or 'slow' hotels that are underpinned by the idea of technological disconnection, and where the over-use of ICT can detrimentally affect the core hotel experience, can benefit from adopting calm ICT design. Similarly, the old-fashioned in-room control devices can be replaced with smart, hyper-personalized hotel experiences controlled with consumer smartphones (Ting, 2017). Yet, the services co-created by hotel management, guests and calm ICT design are rare in existing hotel industry practices (Neuhofer, Buhalis, \& Ladkin, 2014). Branding calm hotel services would imply intentional efforts of hotels to create more complex services based on calm ICT design. Furthermore, calm service cannot solely rely on the digital sphere of hotel products. In order to use calm ICT design, integration of the digital and physical artifacts (e.g. installing mobile applications onto smartphones with subsequent interaction with other devices) is often needed. Evolving from the initial ideas and conceptual modeling of hotel products towards the development of a tangible, real-life product for guests, the future of calm ICT design would anticipate shifts from the digital to the nondigital, more physical solutions (Hohl, 2009). Hence, calm ICT design holds opportunities for new (re-) branding approaches for hotels that go in line with novel technological trends. The proposition of new and uniquely branded calm ICT design based hotel services supports this idea.

\section{Management issues of calm ICT design for hotels}

\section{The challenges of introducing a new ICT design concept in hospitality}

One of the main goals of calm technology is in enabling people to handle vast amounts of information without becoming either overwhelmed with stress or to not become unaware of the world around them (Brown, Fercher, \& Leitner, 2017). In the case of hotel experiences, effective employment of calm ICT design would require understanding of the manifold variables (Gretzel, 2011) which includes, but is not limited to (1) different types of hotel 
experiences and (2) hospitality business models in general, as well as, (3) varied guest preferences towards ICT in hotels.

Hotel experiences are ranging from intimate guesthouse experiences, depersonalized self-service experiences of short says at transit points, high class business experiences to luxury resort experiences with different cognitive, affective, and sensory attributes (Kim \& Perdue, 2013; Ren, Qiu, Wang, \& Lin, 2016) which all require different levels of ICT employment. The development of ICT itself allow some issues of ICT to diminish or disappear, for example context-aware technologies and personalization, coupled with improved the system's quality, new ways of interacting with the system, technical reliability, all help in achieving more calm use of ICT. Novel examples of technology enhanced experiences, simplification and automation of hotel daily operations activities within the context of smart hotel experiences also contribute to this trend (Buhalis \& Leung, 2018). Still, within plethora of existing approaches, the hotel industry-specific implications of generic ICT design for dealing with the overall problems of ICT proliferation still remain poorly understood. Therefore, the introduction of calm ICT design contributes to the agenda of creating non-intrusive technology design so that it becomes an integral part of a guest's experience.

Apart from the level of designing different guest experiences the introduction of calm ICT is facing with infrastructural problems. The procurement of ICT solutions for hotels generally follows the pattern of technology usage among the different hotel groups and their technology knowledge and specialization (Namasivayam, Enz, \& Siguaw, 2000). However, managers should be aware of the specificity of calm ICT design when it is considered an innovation for a hotel. Usually, when adopting calm ICT design, the focus is on the relative advantages that this design can bring over existing ICT solutions (e.g. economic benefits, social prestige, legitimacy or guest convenience) and on the compatibility with existing technological systems and strategies (Namasivayam et al., 2000). Evidently, in the context of calm ICT design, the perceived complexity of innovation technology and its ability to be tested in different contexts should dominate in its evaluation. Unlike the common desire of hotel managers to showcase their investment in innovative technologies, the visibility of calm ICT design is often reduced.

Finally, while information search, paying for services, interacting with in-room appliances and other simple transaction can benefit the most from calm ICT design, direct human contact is still a cornerstone of many aspects of hotel experiences (for example, communicating with front-office or restaurant staff) (Rafat \& Clampet, 2017). In that sense, depending on innovative business strategies of hotels calm ICT design can be seen as a shortterm investment in the new more calm ICT or redesign of existing ones; or as a long-term strategy to prove calm ICT experiences that will help guests in achieving more pleasurable experiences on hotel premises. 
The perspectives of consumer's characteristics that are related to calm ICT usage are discussed in next paragraph.

\section{Varied guest preferences towards calm ICT design in hotels}

There are substantial differences in the extent to which hotel guests are prepared to embrace ICT solutions during their stay. Innovation theory suggests that innovators and early adopters among consumers are more interested in the use of novel technologies (Kah et al., 2008). Amadeus (2015) categorizes hotel guests based on consumer preference for certain types of user experiences (UE) and certain types of desired experiences as facilitated by technology. The categorization spectrum disclosed by Amadeus (2015) stretches from predigital nostalgia consumer groups that will openly deny ICT solution, but still use its benefits for personal gains, to the opposite side of technology addict consumer groups. Furthermore, depending on the context, consumers assign different values to ICT use (Akaka et al., 2012). Some consumers see ICT solutions beneficial while some consider them restrictive (Akaka \& Vargo, 2014). As discussed earlier, the dimension of consumer preferences towards ICT solutions in conjunction with certain contexts of ICT use in hotels can thus lead to dissatisfying guest experiences.

The future development of calm ICT design for hotels will depend on its capacity to be accepted by the end-users (guests) and to be aligned with the producers' interest in the field (Ţugui \& Genete, 2009). Formalization of a calm ICT hotel experience as a theoretical framework could lead to the practical development of the new services that will respect the different consumer needs by concurrently avoiding the problem of technology overload. That would imply inclusion of 'calmness' as a standard variable of consumer perceptions towards ICT when evaluating hotel guest experiences and procuring ICT solutions by hotels.

If offered to the traditionalists, a form of 'calm ICT design barrier' is needed to serve as a buffer zone between ICT intensive hotel guest experience and desired calm experience of the traditionalists. Figure 1 graphically present the amount of hotel interventions in calm ICT design that is needed in response to different guest preferences towards ICT design in hotels . In the case of hotel guests who are highly dependent on technology, this barrier (the level of hotel interventions) can be loosened. Again, in the case of the traditionalists, 'calmness' largely relies upon traditional, one-directed creation of experience which is from a provider to a consumer (Neuhofer et al., 2012). In this case, a hotelier uses technology to aid in the delivery of technology-enhanced staged experiences (Neuhofer et al., 2014). As suggested by Riekki et al. (2004), calm ICT design should bring the systems that do not interfere with endusers unnecessarily, but instead that quietly support end-users by providing the required service, when and if required and without distraction. In this sense, the design of calm ICT services can be driven by hotel guest needs, such as, for instance, the needs of the elderly or 
disabled people as a means to enhance existing hotel experiences. Hotel services designed with this idea in mind could also encompass traditional hotel experiences that are characterized by the limited embracement of technology and restricted business-to-guest and guest-to-guest co-creation. For example, there are some propositions for small hotels to offer silent un-alarm clocks or sleep sensors in the form of bracelets to provide calm ICT experience in its purest form (Little Hotelier, 2015).

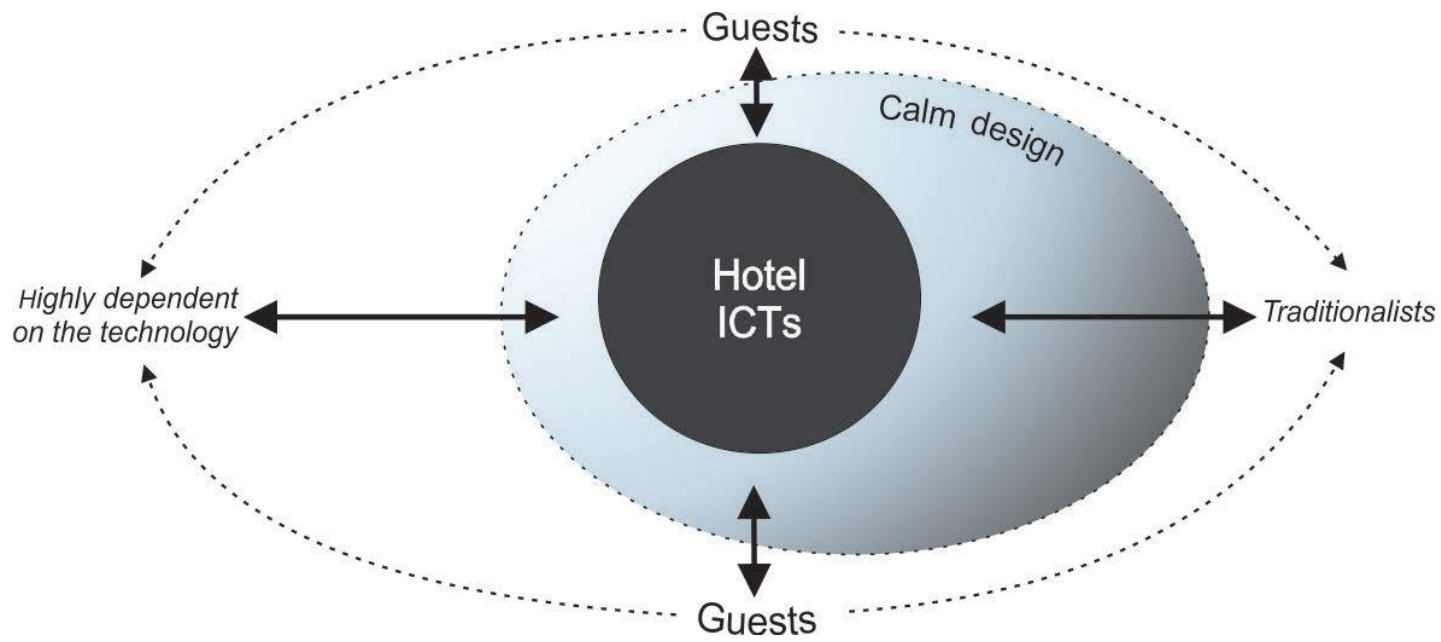

Figure 1. The relations between calm ICT design and varied guest preferences towards ICT

On the other side, hotel services can be created with the more active use of ICT solutions if the guests are familiar with a particular type of technology (Pang, 2011) and its employment will not impose more stress. With the proliferation of ICT there were reports on digitally adept travelers actually expecting and welcoming the high level of ICT-based experiences (Ali, Clampet, Schaal, \& Shankman, 2014). In this case, calm ICT design can enhance consumer experience and engage the hotel guests in experience co-creation. This kind of calmness can be achieved with most of existing technologies as they can be redesigned to provide more engaging environments, similar to those used in everyday life. This can add value by actively embracing the intelligently designed ICT solutions and making them more engaging, thus enabling co-creation in physical and virtual settings and enhancing the hotel guest experience. 


\section{Limitations of calm ICT design for hotels}

510

\section{General constraints and current state of ICT development}

There are general constraints experienced by service providers in their endeavor to adopt new ICT solutions. Wasan (2014) categorizes these constrains as internal barriers (i.e. personal barriers to the ICT adoption, operational barriers, financial barriers, human resources barriers) and external barriers (i.e. market forces, legislation, policies and regulatory standards, customer attitudes, rapidly changing technology, construction challenges). The key challenge for achieving calm ICT design in hotels rests in the scope of currently existing technological limitations. Considerable efforts have gone into realizing the Weiser and Brown's vision in terms of developing frameworks, technologies and infrastructures, including proactive computing, ambient awareness, placing sensors, but, as interesting as these endeavors have been, they still do not match up to the envisioned calm computing (Rogers, 2006). Available technologies are not capable of matching all principles of calm ICT design as the gap between human analogues and computer digital nature remains wide (Greenfield, 2006). When applied to hotels, a prerequisite for the successful calm ICT design implementation can be trivial for certain hotels (i.e. luxury hotels or large hotel chains), but can be crucial for some others. For example, the cost-effective access to Wi-Fi is still a major challenge for smaller, independent hotels and cruises. Furthermore, given its novelty, calm ICT design may require expensive infrastructure which can intensify financial pressures imposed on hotels. This is of special importance for small and medium hotels that make the largest share of the sector.

\section{Vagueness of the concept of calm ICT design for hoteliers and consumers}

At the current state of research, for the majority of hotel guests it would be difficult to identify a desired level of calmness when interacting with ICT solutions. As discussed earlier, calmness is a user's centric measure in a specific usage situation. In this sense, labeling some hotel services based on the level of 'calmness' offered may be appropriate in some cases. For example, a 'tech free' hotel experience can sit on the one side of the spectrum while a 'virtually augmented' hotel experience can represent the other side; these can be branded and offered to the niche tourist segments. Looking from a general perspective, guests from specific geographies, socio-demographic groups, cultural backgrounds or psychographic profiles can be well accustomed to a certain technology while the same technology can be new or confusing for the others (Lo et al., 2002; Benckendorff et al., 2014). For example, social media can deliver desirable and less intrusive messages and hotel alerts to the youngsters which can be seen by this category of consumers as a calm practice; this is because these user groups have by now become 'immune' to the distraction effect of social media (Pang, 2013; Stankov et al., 2014). Concurrently, the older generations could repel 
social media as a communication channel. Furthermore, consumers may expect the different sorts of interaction with technology in various hotel experience's phases as the guests exhibit different user profiles depending on specific situations (Manes, 2001). Technology does not a priori create a value for all kinds of hotel stays, situations and experiences (Neuhofer, 2016). All these aspects need to be recognized and accurately assessed by hoteliers when conceptualizing calm ICT design.

\section{Privacy concerns}

Calm ICT design raises privacy concerns as security of storage of personal information by service providers and the use of different sensors creates a challenge for technology designers and emphasizes the need to develop relevant solutions (Alizadeh et al., 2012). Generally, privacy concerns represent one of the major obstacles in the ICT adoption by hotel guests (Wozniak, Liebrich, Senn, \& Zemp, 2016). The growth of such services as SnapChat and Whispr, or the search engine DuckDuckGo, that do not collect or store personal information, indicate consumer interest in the use of anonymized platforms (Johnston, 2015). Privacy concerns determine why some potentially promising calm technologies have not been empirically realized. Yet, the Google Glass can be used by receptionists in order to identify hotel guests with the help of the facial recognition technology (Udell, 2014). Kim et al. (2013) identified the need for more IT security among hoteliers highlighting a gap between understanding the ICT budget adequacy and the adequacy of installed ICT security systems.

\section{Conclusion and future research needs}

This paper has introduced calm ICT design and explored its applicability to hotels, highlighting the opportunities for its more careful investigation as a means to refine theory and practice of hospitality service provision. The paper has extended the on-going discussion on the role of ubiquitous computing and ambience awareness towards the hotel sector where these topics have not been systematically examined to date. From a practical perspective, a number of implications emerge from this study for the creation of new and for the enhancement of existing hotel guest experience. For hoteliers, this knowledge can advance their understanding of the shortcomings of unselective ICT use for the purpose of creating guest experiences. The previous sections of the paper have elaborated upon calm ICT design in hotels and discussed the key issues that may emerge from its use. In the following, based on earlier analysis, the future research directions are outlined. 
Consumers have been empowered with various ICT solutions, most of which calling for their attention. Instead of being carefully directed towards a certain experience, in this case hotel experience, consumers' attention is now being constantly distracted through the addition of a larger number of ICT solutions. As a process by which people filter internal and external information into their awareness, human attention is, in many aspects, a limited resource and, from the personal and business perspective, it needs to be allocated strategically (Campos, Mendes, do Valle, \& Scott, 2016; Livingstone \& Isaacowitz, 2017; Webster, 2014), especially when it comes to hotel experiences that are, in most cases, limited to a short period of time (Ooi, 2005). Magnini and Dallinger (2018) even indicate that due to modern information overload, the hotel guests are typically not paying full attention as they move through the hotel environments except when something positive or negative happens that they did not expect. Still, the hospitality-specific implications of this limited attention span and its role in ICT design remain poorly understood which opens a broad field for investigation. Research can start by looking at a broad set of methods of human-computer interactions and interaction design (Goodwin, 2009; Nielsen, 2013), especially to identify the key characteristics and generalize the goals of potential consumers, particularly for different hotel types within the process of co-creation experiences (Campos, Mendes, Valle, \& Scott, 2018) (Campos, Mendes, do Valle, Scott, 2018).

\section{Calm ICT design and co-creating digital well-being}

The relevance of calm ICT design is now reconfirmed by the resent market calls and industry responses to information overload and addictive technologies in digitally-led life (Alter, 2018). For example, the new Android operative system is equipped with capabilities to help people achieve the balance with technology usage and this business move is based on the consumers' requests (Samat, 2018). The new concept of the Google's operating system favors so called concept of digital well-being of consumers. The term digital wellbeing describes the framework that "looks after personal health, safety, relationships and work-life balance in digital settings; enables acting safely and responsibly in digital environments; manage digital stress, workload and distraction; uses digital media to participate in political and community actions; uses personal digital data for wellbeing benefits; acts with concern for the human and natural environment when using digital tools; balances digital with real-world interactions appropriately in relationships; etc.” (Beetham, 2016). Digital wellbeing cannot be created solely relying on individual capabilities and therefore is not exclusively individual responsibility (Beetham, 2016; Nansen, Chakraborty, Gibbs, MacDougall, \& Vetere, 2012). Similarly, Gui, Fasoli and Carradore (2017) state that digital wellbeing is a state obtainable not only by the individual personal skills, but also is a societal characteristic that determines 
what is the norm in digital media usage. In case of hotel experiences, the responsibilities are both on the guests as well as hotels that should help in co-creating pleasurable experiences (Harkison, 2018) and limiting all ICT frictions accordingly. Thus, calm ICT design that is provided by hotels but evaluated with the scope of guests' attention can be seen as a hotelindustry response to the growing demand in the global goal of achieving digital wellbeing.

\section{Measuring 'calmness' of hotel guest experience}

Calm ICT design started as a research philosophy, as it was envisioned before the practical realization of the omnipresent Internet, mobile phones and smart devices. Straight from the beginning, there have been attempts to measure 'calmness' of ICT solutions, but these have mostly been unnoticed by industry practitioners and academics. For example, Riekki et al. (2004) presented a framework for evaluating the degree of 'calmness' for ubiquitous applications in the real usage context. The study identified the main characteristics of 'calmness' from the end-user perspective and then utilized these characteristics to define the dimensions for the evaluation. The framework was subjective and 'calmness' was not presented numerically, but shown graphically. Later, Brown et al. (2014) proposed a prototype of quantitative metrics for the evaluation of ICT's calmness based on the Weiser's vision of calm technology and on the principles of anthropology-based computing and peripheral interaction. In its essence, calm ICT design should enable consumers 'to deal with large amounts of information without becoming either overwhelmed by stress or to the world around them' (Brown, 2016). Therefore, quantifying the core dimensions of calm ICT design for enhancing hotel experience is paramount for the evaluation of technological 'calmness' in the hotel context, better understanding of consumer segmentation based on their preferences towards technological 'calmness' and subsequent ICT redesign and new product development for hotels.

\section{Collecting empirical evidence of calm ICT design in hotels}

This paper has showed that calm ICT design in hotels can top the key existing and forthcoming technology support infrastructure. The effectiveness of calm technologies may often be misunderstood or it can be viewed as a question of the common sense. In particular, the principles of calm ICT design can be seen as subjective due to the post-disciplinary nature and the complexity of the approach, ranging from human-centered design, social design, and anthropology (Case, 2015). For example, looking from the calm ICT design perspective, hotel key-cards are small-sized, do not require a charger, user interface or operating system, and they provide convenience for users. However, when applied to hotels, there is at least one new dimension that comes into play - the preferable hotel experience that can be affected by the 'good' or 'bad' ICT design depending on the different contexts of the use and varied guest 
preferences towards technology use. In that sense, consumers who are accustomed to the use of smartphones for paperless transactions or identification in everyday life can find it agitated if they have to pay attention to keeping the key-card during hotel stay. Therefore, in order to avoid the danger of becoming another fuzzy approach, further empirical examination of the feasibility of adopting calm ICT design in hotel experience is needed. More specifically, more research encompassing the examples of existing calm ICT design applications in hotels is required, indicating how the different hotel types can benefit from the broader adoption of this approach. Despite all the challenges, there are good prospects for calm ICT design in hotels given the rapidly changing nature of consumer preferences and the expectations of technology transfers undertaken by hoteliers to manage consumer expectations.

\section{References}

Akaka, M. A., \& Vargo, S. L. (2014). Technology as an operant resource in service (eco)systems. Information

Ali, R., Clampet, J., Schaal, D., \& Shankman, S. (2014). The 14 Trends That Will Define Travel In 2014. Retrieved from http://3rxg9qea18zhtl6s2u8jammft-wpengine.netdna-ssl.com/wpcontent/uploads/2014/01/skift14trends2014.pdf

Alizadeh, S., Kanis, M., \& Veenstra, M. (2012). Using ambient intelligence to support tourism. In A. J. Spink, F. Grieco, O. E. Krips, L. W. S. Loijens, \& P. H. Noldus, L.P.J.J. Zimmerman (Eds.), Proceedings of Measuring Behavior 2012 (pp. 515-519). Utrecht,. Retrieved from http://kennisbank.hva.nl/en/record/514698

Alsetoohy, O., \& Ayoun, B. (2018). Intelligent agent technology: The relationships with hotel food procurement practices and performance. Journal of Hospitality and Tourism Technology, 9(1), 109-124. http://doi.org/10.1108/JHTT-04-2017-0028

Alter, A. L. (2018). Irresistible: The rise of addictive technology and the business of keeping us hooked. London: Penguin Books.

Amadeus. (2007). 2020 Report for the Air Travel Industry. Retrieved from http://www.amadeus.com/documents/future-traveller-tribes-2030/travel-report-future-traveller-tribes2020.pdf

Amadeus. (2015). Future travellers tribes 2030 - Understanding tomorrow's traveller. London. Retrieved from http://www.amadeus.com/documents/future-traveller-tribes-2030/travel-report-future-traveller-tribes2030.pdf

Archpru Akaka, M., Vargo, S. L., \& Lusch, R. F. (2012). An Exploration of Networks in Value Cocreation: A Service-Ecosystems View. In S. L. Vargo \& R. F. Lusch (Eds.), Review of Marketing Research, Volume 9 - Special Issue - Toward a Better Understanding of the Role of Value in Markets and Marketing (pp. 1350). Bingley: Emerald. http://doi.org/10.1108/S1548-6435(2012)0000009006

Assa Abloy. (2003). Elsafe completes their one-million safe installation - ASSA ABLOY Hospitality (VingCard Elsafe). Retrieved March 28, 2017, from http://www.assaabloyhospitality.com/pt-br/aah/com/sala-deimprensa/comunicados-de-imprensa/news/2003/news/elsafe-completes-their-one-million-safe-installation/

Assa Abloy. (2016). New Radisson RED Hotel Employs ASSA ABLOY Hospitality Mobile Access as Key Part of Dedicated Hotel App - Press Release. Retrieved March 28, 2017, from http://ownaedit.assaabloy.com/Other/VingCardElsafe/File Archive/.com Archive/Press 
Releases/2016/AAH-Radisson-Red-PR.pdf

Atembe, R. (2015). The Use of Smart Technology in Tourism: Evidence From Wearable Devices. Journal of Tourism and Hospitality Management, 3(6), 224-234. http://doi.org/10.17265/2328-2169/2015.12.002

Babu, P. (2015). Beacons in Tourism and Travel. Retrieved August 8, 2016, from http://blog.beaconstac.com/2015/11/how-beacons-are-transforming-the-travel-industry/

Balasubramanian, S. (2009). Mobile Marketing: A Synthesis and Prognosis. Journal of Interactive Marketing, 23(2), 118-129. http://doi.org/10.1016/j.intmar.2009.02.002

Beetham, H. (2016). What is “Digital Wellbeing”? Retrieved August 8, 2018, from http://design-4learning.blogspot.com/2016/03/what-is-digital-wellbeing.html

Benckendorff, P. J., Sheldon, P. J., \& Fesenmaier, D. R. (2014). Tourism Information Technology. Oxfordshire: CABI.

Bibri, S. E. (2015). The Shaping of Ambient Intelligence and the Internet of Things. Paris: Atlantis Press.

Bilgihan, A., Karadag, E., Cobanoglu, C., \& Okumus, F. (2013). Research Note: Biometric Technology Applications and Trends in Hotels. Hospitality Review, 31(2), 9-24.

Bilolo, A., Boeck, H., Durif, F., Levesque, N., \& Levesque, N. (2015). The Impact of Proximity Marketing on Consumer Reactions and Firm Performance: A Conceptual and Integrative Model. In Twenty-first Americas Conference on Information Systems - AMCIS 2015 Proceedings (pp. 1-8). Puerto Rico.

Brown, J. N. A. (2016). Getting Excited About “Calm Technology.” In J. N. A. Brown (Ed.), AnthropologyBased Computing (pp. 23-34). Cham: Springer.

Brown, J. N. A., Bayerl, P. S., Fercher, A., Leitner, G., Catala Mallore, A., \& Hitz, M. (2014). A Measure of Calm. In ACM CHI Conference on Human Factors in Computing Systems. Retrieved from http://peripheralinteraction.id.tue.nl/chi/paper/CHIWorkshop_PI_Brown2.pdf

Brown, J. N. A., Fercher, A. J., \& Leitner, G. (2017). “Just the Place for a Snark!”: An Introduction to Calm Technology. In J. N. . Brown, A. J. Ferchera, \& G. Leitner (Eds.), Building an Intuitive Multimodal Interface for a Smart Home (pp. 17-20). Cham: Springer.

Buhalis, D., \& Leung, R. (2018). Smart hospitality—Interconnectivity and interoperability towards an ecosystem. International Journal of Hospitality Management, 71, 41-50. http://doi.org/10.1016/J.IJHM.2017.11.011

Byrne C., O’Grady M. \& O’Hare, G. (2009). Ambient Intelligence in Perspective. In J. Symonds (Ed.), Ubiquitous and Pervasive Computing: Concepts, Methodologies, Tools, and Applications (pp. 129-136). IGI Global: Harshey. https://doi.org/10.4018/978-1-60566-960-1.ch011.

Campos, A. C., Mendes, J., do Valle, P. O., \& Scott, N. (2016). Co-Creation Experiences: Attention and Memorability. Journal of Travel \& Tourism Marketing, 33(9), 1309-1336. http://doi.org/10.1080/10548408.2015.1118424

Campos, A. C., Mendes, J., Valle, P. O. do, \& Scott, N. (2018). Co-creation of tourist experiences: a literature review. Current Issues in Tourism, 21(4), 369-400. http://doi.org/10.1080/13683500.2015.1081158

Case, A. (2015). Calm technology : principles and patterns for non-intrusive design. Sebastopol: CA: O’Reilly Media, Inc,.

Cetin, G., \& Walls, A. (2016). Understanding the Customer Experiences from the Perspective of Guests and Hotel Managers: Empirical Findings from Luxury Hotels in Istanbul, Turkey. Journal of Hospitality Marketing \& Management, 25(4), 395-424. http://doi.org/10.1080/19368623.2015.1034395

Chan, M., Estève, D., Fourniols, J.-Y., Escriba, C., \& Campo, E. (2012). Smart wearable systems: Current status and future challenges. Artificial Intelligence in Medicine, 56(3), 137-156. http://doi.org/10.1016/j.artmed.2012.09.003

Chen, M.-M., Murphy, H. C., \& Knecht, S. (2016). An Importance Performance Analysis of smartphone applications for hotel chains. Journal of Hospitality and Tourism Management, 29, 69-79. 
Chiu, D. K. W., \& Leung, H. (2005). Towards Ubiquitous Tourist Service Coordination and Integration: a Multi-Agent and Semantic Web Approach semantic web services. In Proceedings of the 7th international conference on Electronic commerce - ICEC '05 (pp. 574-581). New York, New York, USA: ACM Press. http://doi.org/10.1145/1089551.1089656

Choe, Y., \& Fesenmaier, D. R. (2017). The Quantified Traveler: Implications for Smart Tourism Development. In Z. Xiang \& D. R. Fesenmaier (Eds.), Analytics in Smart Tourism Design (pp. 65-77). Springer International Publishing. http://doi.org/10.1007/978-3-319-44263-1_5

Chung, N., \& Lee, H. (2016). Sharing economy in geotag: what are the travelers' goals sharing their locations by using geotags in social network sites during the tour? International Journal of Tourism Cities, 2(2), 125136. http://doi.org/10.1108/IJTC-08-2015-0022

Chung, N., Tyan, I., \& Han, H. (2017). Enhancing the smart tourism experience through geotag. Information Systems Frontiers, 19(4), 731-742. http://doi.org/10.1007/s10796-016-9710-6

Cisco. (2015). Creating the digital hotel of the future. Retrieved March 28, 2017, from http://www.cisco.com/c/dam/en_us/solutions/industries/docs/trec/hyatt_cisco_digital.pdf

Clark, A. (2014). How emoji became the first truly global language | Technology | The Guardian. Retrieved from https://www.theguardian.com/technology/2014/aug/31/emoji-became-first-global-language

Cobanoglu, C., Berezina, K., Kasavana, M. L., \& Erdem, M. (2011). The Impact of Technology Amenities on Hotel Guest Overall Satisfaction. Journal of Quality Assurance in Hospitality \& Tourism, 12(4), 272-288. http://doi.org/10.1080/1528008X.2011.541842

Cousins, C. (2015). Google Material Design: Everything You Need to Know | Design Shack. Retrieved August 8, 2016, from https://designshack.net/articles/ux-design/google-material-design-everything-you-need-toknow/

Dibble, T. (2015). Technology is changging travel. Retrieved July 18, 2015, from https://www.screenpilot.com/2015/03/wearables-wanderlust-how-technology-is-changing-travel/

Dickinson, J. E., Ghali, K., Cherrett, T., Speed, C., Davies, N., \& Norgate, S. (2014). Tourism and the smartphone app: capabilities, emerging practice and scope in the travel domain. Current Issues in Tourism, 17(1), 84-101. http://doi.org/http://dx.doi.org/10.1080/13683500.2012.718323

Elwood, S. A. (2010). Embedding Ubiquitous Technologies. In J. Symonds (Ed.), Ubiquitous and Pervasive Computing: Concepts, Methodologies, Tools, and Applications (pp. 511-519). Hershley: IGI Global. http://doi.org/10.4018/978-1-60566-960-1.ch033

Eye for Travel. (2016). Talking technology: is this what hotel guests really want? Retrieved August 8, 2016, from http://www.eyefortravel.com/mobile-and-technology/talking-technology-what-hotel-guests-reallywant

Frı́s, D. M. A., Rodruez, M. A., \& Castanda, J. A. (2008). Internet vs . travel agencies on pre - visit destination image formation: An information processing view. Tourism Management, 29, 163-179.

Giebelhausen, M. D. (2014). Cyborg service: The unexpected effect of technology in the employee-guest exchange [Electronic version]. Center for Hospitality Research Report, 14(19), 4-13. Retrieved from http://scholarship.sha.cornell.edu/reports

Glaros, C., \& I. Fotiadis, D. (2005). Wearable Devices in Healthcare. In B. G. Silverman, A. Jain, A. Ichalkaranje, \& L. C. Jain (Eds.), Intelligent Paradigms for Healthcare Enterprises (pp. 237-264). Heidelberg: Springer Berlin . http://doi.org/10.1007/11311966_8

Goodwin, K. (2009). Designing for the digital age: How to create human-centered products and services. Indianapolis,: Wiley Pub.

Greenfield, A. (2006). Everyware The dawning age of ubiquitous computing. Berkley: New Riders.

Gretzel, U. (2011). Intelligent systems in tourism. Annals of Tourism Research, 38(3), 757-779. 
http://doi.org/10.1016/j.annals.2011.04.014

Grossman, A. (2015). Forecast Blog: Dark Sky 5. Retrieved September 3, 2015, from http://blog.forecast.io/dark-sky-5/

Gui, M., Fasoli, M., \& Carradore, R. (2017). Digital Well-Being. Developing a New Theoretical Tool For Media Literacy Research. Italian Journal of Sociology of Education, 9(1), 155-173. http://doi.org/10.14658/pupjijse-2017-1-8

Gustaffo. (2018). Exhibitor profile. Retrieved from https://www.virtualmarket.itb-berlin.de/en/Gustaffo-digitalservice-GmbH,c487620

Hardy, A., Hyslop, S., Booth, K., Robards, B., Aryal, J., Gretzel, U., \& Eccleston, R. (2017). Tracking tourists' travel with smartphone-based GPS technology: a methodological discussion. Information Technology \& Tourism, 1-20. http://doi.org/10.1007/s40558-017-0086-3

Harkison, T. (2018). The use of co-creation within the luxury accommodation experience - myth or reality? International Journal of Hospitality Management, 71, 11-18. http://doi.org/10.1016/J.IJHM.2017.11.006

Hermans B. (1998). Desperately Seeking: Helping Hands and Human Touch. First Monday, 3 (11), https://doi.org/10.5210/fm.v3i11.626.Hohl, M. (2009). Calm Technologies 2.0: Visualising Social Data as an Experience in Physical Space. Parsons Journal for Information Mapping, 1(3), 1-7.

Johnston, N. (2015). Adaptive Marketing. New York: Palgrave Macmillan US. http://doi.org/10.1057/9781137462930

Kah, J. A., Vogt, C., \& MacKay, K. (2008). Online Travel Information Search and Purchasing by Internet Use Experiences. Information Technology \& Tourism, 10(3), 227-243.

Kang, B., Brewer, K. P., \& Bai, B. (2007). Biometrics for Hospitality and Tourism: A New Wave of Information Technology. Hospitality Review, 25(1), 1-9.

Kim, D., \& Perdue, R. R. (2013). The effects of cognitive, affective, and sensory attributes on hotel choice. International Journal of Hospitality Management, 35, 246-257. http://doi.org/10.1016/J.IJHM.2013.05.012

Kim, H. H., \& Law, R. (2015). Smartphones in Tourism and Hospitality Marketing: A Literature Review. Journal of Travel \& Tourism Marketing, 32(6), 692-711. http://doi.org/10.1080/10548408.2014.943458

Kim, J., Farrish, J., \& Schrier, T. (2013). Hotel Information Technology Security: Do Hoteliers Understand the Risks? International Journal of Hospitality \& Tourism Administration, 14(3), 282-304. http://doi.org/10.1080/15256480.2013.809992

Kronsberg, M. (2016). Are High-Tech Hotels Alluring —or Alienating? Retrieved March 30, 2017, from https://www.wsj.com/articles/are-high-tech-hotels-alluringor-alienating-1461866041

Law, R., Buhalis, D., \& Cobanoglu, C. (2014). Progress on information and communication technologies in hospitality and tourism. International Journal of Contemporary Hospitality Management, 26(5), 727-750. http://doi.org/10.1108/IJCHM-08-2013-0367

Lee H. and Kwon, J. (2010). Combining Context-Awareness with Wearable Computing for Emotion-based Contents Service. International Journal of Advanced Science and Technology, 22, 13-24.Lee, O., \& Oh, J.-E. (2007). The Impact of Virtual Reality Functions of a Hotel Website on Travel Anxiety. CyberPsychology \& Behavior, 10(4), 584-586. http://doi.org/10.1089/cpb.2007.9987

Lee, Y.-K., Chang, C.-T., Lin, Y., \& Cheng, Z.-H. (2014). The dark side of smartphone usage: Psychological traits, compulsive behavior and technostress. Computers in Human Behavior, 31, 373-383. http://doi.org/10.1016/j.chb.2013.10.047

Lim W.M., Teh P.-L., Ahmed P.K., Cheong S.-N., Ling H.-C. and Yap, W.-J. (2018). Going keyless for a seamless experience: Insights from a unified hotel access control system. International Journal of Hositality Management, 75, 105-115. https://doi.org/10.1016/J.IJHM.2018.03.014.

Lippe-McGraw, J. (2017). Where to Go for a Silent Retreat - Condé Nast Traveler. Retrieved January 24, 2018, 

from https://www.cntraveler.com/story/silent-retreats-are-the-latest-in-digital-detox-vacations

Little Hotelier. (2015). Wearable Technology for Small Hotels: Our Top 3 Examples. Retrieved January 31, 2017, from http://www.littlehotelier.com/small-hotel-technology/3-examples-wearable-technology-mightmean-small-hotel-marketer/

Littlehotelier. (2015). Wearable Technology for Small Hotels: Our Top 3 Examples. Retrieved March 29, 2017, from http://www.littlehotelier.com/r/small-hotel-technology/3-examples-wearable-technology-mightmean-small-hotel-marketer/

Livingstone, K. M., \& Isaacowitz, D. M. (2017). Attention, Emotion, and Well-Being: An Adult Lifespan Perspective. In M. D. Robinson \& M. Eid (Eds.), The Happy Mind: Cognitive Contributions to Well-Being (pp. 23-39). Cham: Springer International Publishing. http://doi.org/10.1007/978-3-319-58763-9_2

Lo, A., Cheung, C., \& Law, R. (2002). Information search behavior of Hong Kong's inbound travelers - -a comparison of business and leisure travelers. Journal of Travel \& Tourism Marketing, 13(3), 61-81. http://doi.org/10.1080/10548400209511568

Lunny, O. (2016). Mobile App Saturation: What's Next in Customer Engagement Trends - Digital Doughnut. Retrieved January 22, 2018, from https://www.digitaldoughnut.com/articles/2016/july/mob-appsaturation-whats-next-customer-engagement

Magnini, V. P., \& Dallinger, I. (2018). Consumer Information Overload and the Need to Prompt Script Deviations. Journal of Quality Assurance in Hospitality \& Tourism, 19(3), 285-297. http://doi.org/10.1080/1528008X.2016.1230038

Manes, G. (2001). The Tetherless Tourist: Ambient Intelligence in Travel \& Tourism. Information Technology \& Tourism, 5(4), 211-220.

Meyers, M., \& Mills, E. J. (2005). Are Biometric Technologies The Wave of the Future in Tourism and Hospitality? West Lafayette, IN. Retrieved from https://www.researchgate.net/publication/237641609_Are_Biometric_Technologies_The_Wave_of_the_F uture_in_Tourism_and_Hospitality

Mills, J. E., Meyers, M., \& Byun, S. (2010). Embracing broadscale applications of biometric technologies in hospitality and tourism. Journal of Hospitality and Tourism Technology, 1(3), 245-256. http://doi.org/10.1108/17579881011078377

Moraveji N., Oshidary N., Pea R. \&Fogg, B. (2011). Calming Technologies. In CHI 2011 Workshop - Personal Informatics \& HCI: Design, Theory, \& Social Implications. Vancouver. Retrieved from http://lifeslc.org/docs/LSLC_rp_A174_Moraveji_etal_Calmingtech_CHI2011.pdf.

Murphy, H. C., Chen, M.-M., \& Cossutta, M. (2016). An investigation of multiple devices and information sources used in the hotel booking process. Tourism Management, 52, 44-51. http://doi.org/10.1016/J.TOURMAN.2015.06.004

Namasivayam, K., Enz, C. A., \& Siguaw, J. A. (2000). How wired are we? Selection and use of new technology in U.S. hotels. The Cornell Hotel and Restaurant Administration Quarterly, 41(6), 40-48. http://doi.org/10.1016/S0010-8804(00)89021-7

Nansen, B., Chakraborty, K., Gibbs, L., MacDougall, C., \& Vetere, F. (2012). Children and Digital Wellbeing in Australia: Online regulation, conduct and competence. Journal of Children and Media, (2), 237-254. http://doi.org/10.1080/17482798.2011.619548

Neo, H.-F., Rasiah, D., Tong, D. Y. K., \& Teo, C.-C. (2014). Biometric technology and privacy: a perspective from tourist satisfaction. Information Technology \& Tourism, 14(3), 219-237. http://doi.org/10.1007/s40558-014-0014-8

Neuhofer, B. (2016). Value Co-creation and Co-destruction in Connected Tourist Experiences. In A. Inversini \& R. Schegg (Eds.), Information and Communication Technologies in Tourism 2016 (pp. 779-792). Cham: Springer International Publishing. http://doi.org/10.1007/978-3-319-28231-2_56

Neuhofer, B., Buhalis, D., \& Ladkin, A. (2012). Conceptualising technology enhanced destination experiences. Journal of Destination Marketing \& Management, 1(1), 36-46. http://doi.org/10.1016/j.jdmm.2012.08.001 
Neuhofer, B., Buhalis, D., \& Ladkin, A. (2014). A Typology of Technology-Enhanced Tourism Experiences. International Journal of Tourism Research, 16(4), 340-350. http://doi.org/10.1002/jtr.1958

Neuhofer, B., Buhalis, D., \& Ladkin, A. (2015). Smart technologies for personalized experiences: a case study in the hospitality domain. Electronic Markets, 25(3), 243-254. http://doi.org/10.1007/s12525-015-0182-1

Nielsen, L. (2013). Personas - User focused design. London: Springer Verlang.

Ocallaghan, K. (2014). Rejoice: Tomorrow’s Tech Will Probably Stop Nagging Us. Retrieved June 24, 2018, from https://www.wired.com/2014/11/invisible-technology/

Ooi, C.-S. (2005). A Theory of Tourism Experiences: The Management of Attention. In T. O’Dell \& P. Billing (Eds.), Experiencescapes: Tourism, Culture and Economy (pp. 51-68). Herndon: Copenhagen Business School Press.

Ortiz Rincon, F., Tommasini, E., Rainoldi, M., \& Egger, R. (2017). The Future of Wearable Devices On-Site: A Scenario Technique Approach. In R. Schegg \& B. Stangl (Eds.), Information and Communication Technologies in Tourism 2017 (pp. 285-299). Cham: Springer International Publishing.

Palladium Hotel Group. (n.d.). Palladium Hotel Group introduces 'VIB' smart bracelets at Ushuaïa Ibiza Beach Hotel \&amp; the new Hard Rock Hotel Ibiza. Retrieved March 28, 2017, from http://www.palladiumhotelgroup.com/en/palladium/prensa/bracelets/

Pang, A. S.-K. (2011). On “calmness” and computing. Retrieved July 7, 2016, from http://www.contemplativecomputing.org/2011/01/on-calmness-and-computing.html

Pang, A. S.-K. (2013). The distraction addiction : getting the information you need and the communication you want without enraging your family, annoying your colleagues, and destroying your soul. New York: Little Brown and Company.

Pesonen, J., \& Horster, E. (2012). Near field communication technology in tourism. Tourism Management Perspectives, 4, 11-18. http://doi.org/10.1016/j.tmp.2012.04.001

Picard R.W. (1995), Affective Computing. M.I.T Media Laboratory Perceptual Computing Section Technical Report No. 321. Retrieved from http://vismod.media.mit.edu/tech-reports/TR-321.pdf.

Pizam, A. (2010). Creating memorable experiences. International Journal of Hospitality Management. http://doi.org/10.1016/j.ijhm.2010.04.003

Plé, L., \& Chumpitaz Cáceres, R. (2010). Not always co value in service JdømialaoftSegioces Marketing, 24(6), 430-437. http://doi.org/10.1108/08876041011072546

Rafat, A., \& Clampet, J. (2017). Travel Megatrends 2017: Humanity Returns to Travel. Retrieved August 20, 2018, from https://skift.com/2017/01/13/travel-megatrends-2017-humanity-returns-to-travel/

Raz, N. (2016). Amazon Echo a ‘game-changer’ for Wynn Las Vegas | Las Vegas Review-Journal. Retrieved March 28, 2017, from http://www.reviewjournal.com/business/casinos-gaming/amazon-echo-gamechanger-wynn-las-vegas

Reeves, F. (2018). How Artificial Intelligence will bring the human touch back to hotels | TravelDailyNews International. Retrieved June 24, 2018, from https://www.traveldailynews.com/post/how-artificialintelligence-will-bring-the-human-touch-back-to-hotels

Ren, L., Qiu, H., Wang, P., \& Lin, P. M. C. (2016). Exploring customer experience with budget hotels: Dimensionality and satisfaction. International Journal of Hospitality Management, 52, 13-23. http://doi.org/10.1016/J.IJHM.2015.09.009

Riekki, J., Isomursu, P., \& Isomursu, M. (2004). Evaluating the Calmness of Ubiquitous Applications. In F. Bomarius \& H. Iida (Eds.), Product Focused Software Process Improvement (pp. 105-119). Berlin: Springer Berlin Heidelberg. http://doi.org/10.1007/978-3-540-24659-6_8

Robins, B., \& Dautenhahn, K. (2014). Tactile Interactions with a Humanoid Robot: Novel Play Scenario Implementations with Children with Autism. International Journal of Social Robotics, 6(3), 397-415. 
Rogers, Y. (2006). Moving on from Weiser's Vision of Calm Computing: Engaging UbiComp Experiences. In P. Dourish \& A. Friday (Eds.), UbiComp 2006: Ubiquitous Computing (Vol. 4206, pp. 404-421). Berlin: Springer-Verlag.

Samat, S. (2018). Android 9 Pie: Powered by AI for a smarter, simpler experience that adapts to you. Retrieved August 20, 2018, from https://blog.google/products/android/introducing-android-9-pie/

Sarmah, B., Kamboj, S., \& Rahman, Z. (2017). Co-creation in hotel service innovation using smart phone apps: an empirical study. International Journal of Contemporary Hospitality Management, 29(10), 2647-2667. http://doi.org/10.1108/IJCHM-12-2015-0681

Sension. (2018). Invisible technology, best technology. Retrieved June 24, 2018, from https://senion.com/insights/invisible-technology-best-technology/

Sharkey, A., \& Sharkey, N. (2012). Granny and the robots: ethical issues in robot care for the elderly. Ethics and Information Technology, 14(1), 27-40. http://doi.org/10.1007/s10676-010-9234-6

Sigala, M. (2018). New technologies in tourism: From multi-disciplinary to anti-disciplinary advances and trajectories. Tourism Management Perspectives. http://doi.org/10.1016/j.tmp.2017.12.003

Stanford University's Calming Technology Lab. (2011). Calming Technology: So what are "calm" technologies, then?. Retrieved from http://calmingtechnology.org/post/48795961169/so-what-are-calmtechnologies-then

Stankov, U., Jovanović, T., \& Dragićević, V. (2014). Facebook Travel Related Usage Patterns of Tourism Students. In SINTEZA 2014 Impact of Internet on Business activities in Serbia and Worldwide (pp. 743749). Belgrade. http://doi.org/10.15308/SInteZa-2014-743-749

Stankov, U., Pavluković, V., Alcántara-Pilar, J. M., Cimbaljević, M., \& Armenski, T. (2018). Should Festival Be Smarter? ICT on Mass Events - The Case of the Exit Festival (Novi Sad, Serbia). In J. M. . Rodrigues, C. M. . Ramos, P. J. . Cardoso, \& C. Henriques (Eds.), Handbook of Research on Technological Developments for Cultural Heritage and eTourism Applications (pp. 245-263). Hershey: IGI Global.

Streitz, N. A. (2001). Mental vs. Physical Disappearance: The Challenge of Interacting with Disappearing Computers. In Workshop Proceedings Distributed and disappearing user interfaces in ubiquitous computing CHI01. Seatle. Retrieved from http://www.teco.kit.edu/chi2001ws/20_streitz.pdf

Sweterlitsch, H. (2016). HackerAgency - IoT: Invisible, Calm Mrktg. Retrieved August 28, 2015, from http://hal2l.com/invisible-calm-atmospheric-the-future-of-marketing

Tarlow, P. (2011). The World of Technology Affects Tourism Industry Immensely. Retrieved August 11, 2016, from http://www.tourism-review.com/the-world-of-technology-affects-tourism-industry-immenselynews2757

Thakkar, D. (2016). Biometric Security for the Hospitality Industry. Retrieved March 28, 2017, from https://www.bayometric.com/biometric-security-for-the-hospitality-industry/

The Japan News. (2016). Fingerprints to be tested as 'currency' - The Japan News. Retrieved from http://thejapan-news.com/news/article/0002859676

Ting, D. (2016). The Current State of Keyless Entry at Big Hotel Brands. Retrieved August 8, 2016, from https://skift.com/2016/06/29/the-current-state-of-keyless-entry-at-big-hotel-brands/

Ting, D. (2017). Hilton and Marriott Turn to the Internet of Things to Transform the Hotel Room Experience Skift. Retrieved January 21, 2018, from https://skift.com/2017/11/14/hilton-and-marriott-turn-to-theinternet-of-things-to-transform-the-hotel-roomexperience/?utm_campaign=Skift+Weekly+Review+Newsletter\&utm_source=hs_email\&utm_medium=e mail\&utm_content $=58582227 \&$ _hsenc $=$ p2ANqtz-995LBsT9BttGZwYoYw

Țugui, A., \& Genete, L.-D. (2009). Information Technologies in the Calm Technologies Era. Communications of the IBIMA, 8, 120-127. 
Tussyadiah, I. (2013). Expectation of Travel Experiences with Wearable Computing Devices. In Z. Xiang \& I. Tussyadiah (Eds.), Information and Communication Technologies in Tourism 2014 (pp. 539-552). Cham: Springer International Publishing. http://doi.org/10.1007/978-3-319-03973-2_39

Udell, S. (2014). Hotel Software Defies Google Glass’ Facial Recognition Ban. Retrieved August 6, 2016, from http://glassalmanac.com/hotel-software-defies-facial-recognition-ban/4407/

Walls, A., Okumus, F., Wang, Y. (Raymond), \& Kwun, D. J.-W. (2011). Understanding the Consumer Experience: An Exploratory Study of Luxury Hotels. Journal of Hospitality Marketing \& Management, 20(2), 166-197. http://doi.org/10.1080/19368623.2011.536074

Wang, Z., Zhu, W., Cui, P., Sun, L., \& Yang, S. (2013). Social Media Recommendation. In N. Ramzan, R. van Zwol, J.-S. Lee, K. Clüver, \& X.-S. Hua (Eds.), Social Media Retrieval (pp. 23-42). London: Springer Verlang. http://doi.org/10.1007/978-1-4471-4555-4_2

Wasan, P. (2014). Sustainable Technology in Hospitality Industry. In V. Jauhari (Ed.), Managing Sustainability in the Hospitality and Tourism Industry Paradigms and Directions for the Future (pp. 101-135). Boca Raton, FL; Oakville, ON: CRC Press; Apple Academic Press. http://doi.org/10.1046/9999-9999.99999

Webster, J. G. (2014). The Marketplace of Attention: How Audiences Take Shape in a Digital Age. Cambridge: MIT Press.

Weiser, M. (1993). Perspectives article for ACM Interactions. Retrieved from http://www.ubiq.com/hypertext/weiser/ACMInteractions2.html

Weiser, M., \& Brown, J. S. (1995). Designing Calm Technology. Retrieved May 5, 2016, from http://www.ubiq.com/weiser/calmtech/calmtech.htm

Whitelaw, P. A. (2008). ICT and hospitality operations. In P. Jones (Ed.), Handbook of Hospitality Operations and IT (pp. 167-184). Oxford: Butterworth-Heinemann. http://doi.org/10.1016/B978-0-7506-87539.50012-3

Williams, O. (2015). Hyde Park visitors covertly tracked via mobile phone data. Retrieved July 18, 2015, from https://www.theguardian.com/world/2015/dec/25/hyde-park-visitors-tracked-mobile-phone-data-ee

Wozniak, T., Liebrich, A., Senn, Y., \& Zemp, M. (2016). Alpine Tourists’ Willingness to Engage in Virtual CoCreation of Experiences. In A. Inversini \& R. Schegg (Eds.), Information and Communication Technologies in Tourism 2016 (pp. 281-294). Cham: Springer International Publishing. http://doi.org/10.1007/978-3-319-28231-2_21

Yamamoto, G. T. (2009). Mobilized Marketing and the Consumer: Technological Developments and Challenges. http://services.igi-global.com/resolvedoi/resolve.aspx?doi=10.4018/978-1-60566-916-8. Harshley: Busniess Science Reference.

Yovcheva Z., Buhalis D. \& Gatzidis, C. (2012). Overview of Smartphone Augmented Reality Applications for Tourism. e-Review of Tourism Research, 10 (2) 63-66. 